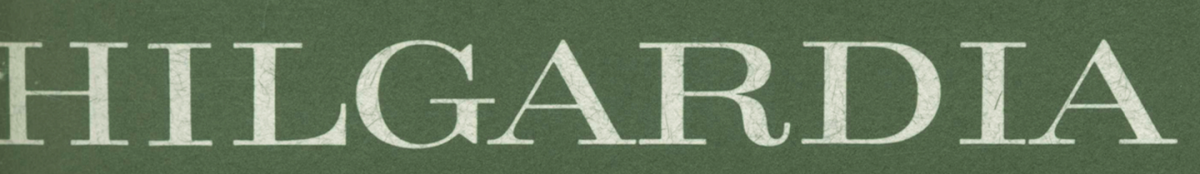

A JOURNAL OF AGRICULTURAL SCIENCE PUBLISHED BY THE CALIFORNIA AGRICULTURAL EXPERIMENT STATION

Volume 35, Number $12 \cdot$ March, 1964

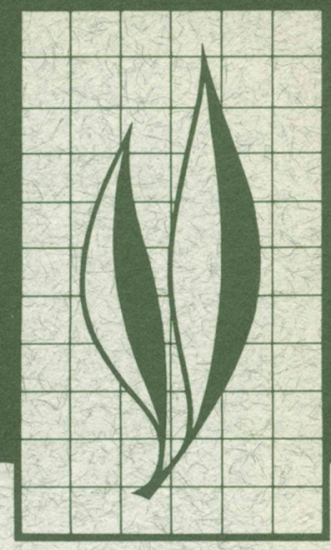

\title{
Severe Copper Deficiency in Orchard Grapefruit Trees
}

\author{
G. R. Bradford, R. B. Harding \\ and M. P. Miller
}




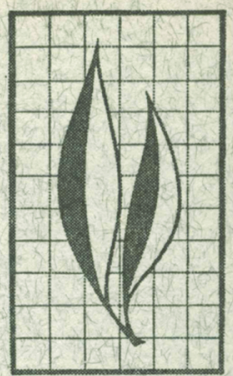

\section{THE AUTHORS:}

G. R. Bradford is Associate Specialist in the Experiment Station, Riverside; R. B. Harding is Associate Chemist in the Experiment Station, Riverside; M. P. Miller is Agriculturist in the Extension Service, Riverside. 


\section{Severe Copper Deficiency in Orchard Grapefruit Trees ${ }^{1,2}$}

\section{INTRODUCTION}

IN THE WINTER of 1958 several grapefruit orchards near Hemet, California, developed severe copper deficiency symptoms. Because this deficiency is rarely seen in the field in California, its appearance in severe form presented an excellent opportunity for study of the diagnostic symptoms, for laboratory verification through leaf and soil analysis, and for field correction of the deficiency. This paper is a report of copper-deficiency symptoms as they appeared in the grapefruit, and of the use of sprays to achieve full recovery.

\section{MATERIALS AND METHODS}

\section{Experimental Orchards}

The three grapefruit orchards studied are located on Hanford sandy loam soil. Orchard A comprised 27 acres of Ruby red grapefruit scion on rough lemon rootstock, while orchard B comprised about 10 acres of Marsh grapefruit scion on rough lemon rootstock. Adjacent to these 10 acres of grapefruit were about 5 acres of Valencia oranges (orchard C) on rough lemon rootstock. Orchard D was a poor-appearing young grapefruit orchard (rootstock unknown) located about a mile south of orchard C.

\section{Leaf Sampling and Analysis}

Spring cycle leaves 4 to 6 months old were taken from fruiting terminals. In each case 10 leaves from each of 10 trees comprised the sample. Leaves were individually washed in tap water and
Ivory soap, rinsed in tap water, and dried with clean cloths; this method of leaf washing has been employed in laboratories of the department of Soils and Plant Nutrition at Riverside, California for many years and has been subjected to thorough testing (Wallihan, 1953). The samples were then oven dried at $55^{\circ}$ $\mathrm{C}$ and crumbled by hand previous to weighing a 2-gram sample for spectrographic analysis. Micro-element determinations were made by the spectrochemical method of Vanselow et al. (1948).

\section{Soil Sampling and Analysis}

Virgin soil samples of the 6 to 8 -inches depth were collected from areas surrounding the orchards showing severe copper deficiency symptoms. Samples were analyzed for total copper by the method of Pratt and Bradford (1958).

\footnotetext{
${ }^{1}$ Submitted for publication June 7, 1963.

2 Paper No. 1497 of the California Citrus Research Center and Agricultural Experiment Station, Riverside, California.

"See "Literature Cited" for citations referred to in the text by author and date.
} 


\section{RESULTS AND DISCUSSION}

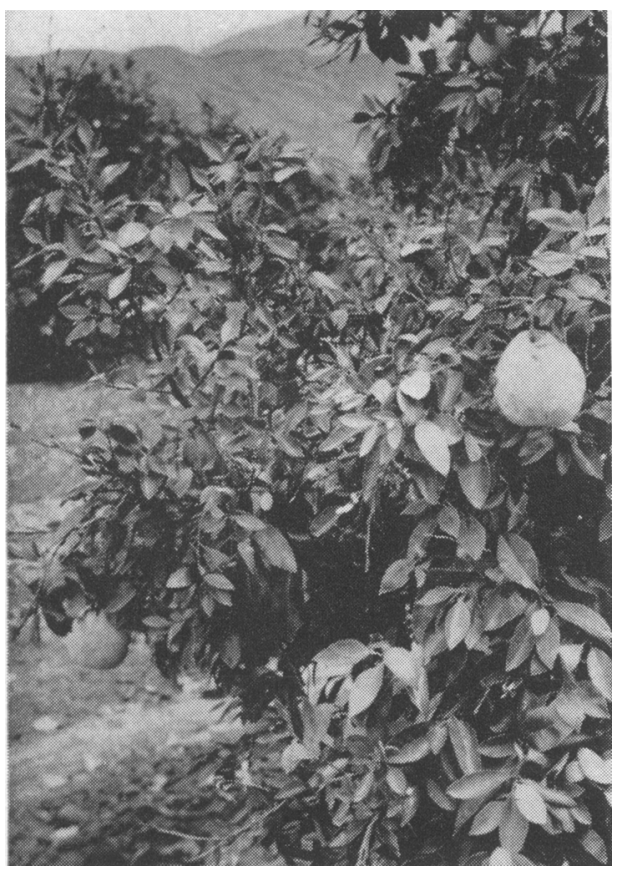

Fig. 1. Grapefruit tree with severe copper deficiency.
The generally poor condition of orchard A was first observed in February, 1958. The unhealthy appearance of the trees was originally attributed to low winter temperatures, but careful examination of the orchard revealed considerable twig dieback and chlorotic leaves on trees growing at higher, frost-free elevations. Many of the leaves were irregular in contour and tended to "bowup" along the midrib, a copper deficiency symptom reported by Camp et al. (1949). Most of the fruit throughout the orchard was so misshapen and coarse as to be unmarketable. The peel was abnormally thick and pulpy. Brown blotches or necrotic spots were observed on the outside of the fruit (fig. 2) and gum pockets or brown areas of discoloration were observed on the inside of the fruit (fig. 3). Gumming on twigs, a typical symptom of copper deficiency reported from other citrus growing areas by Camp et al. (1949), was not noted during this study.

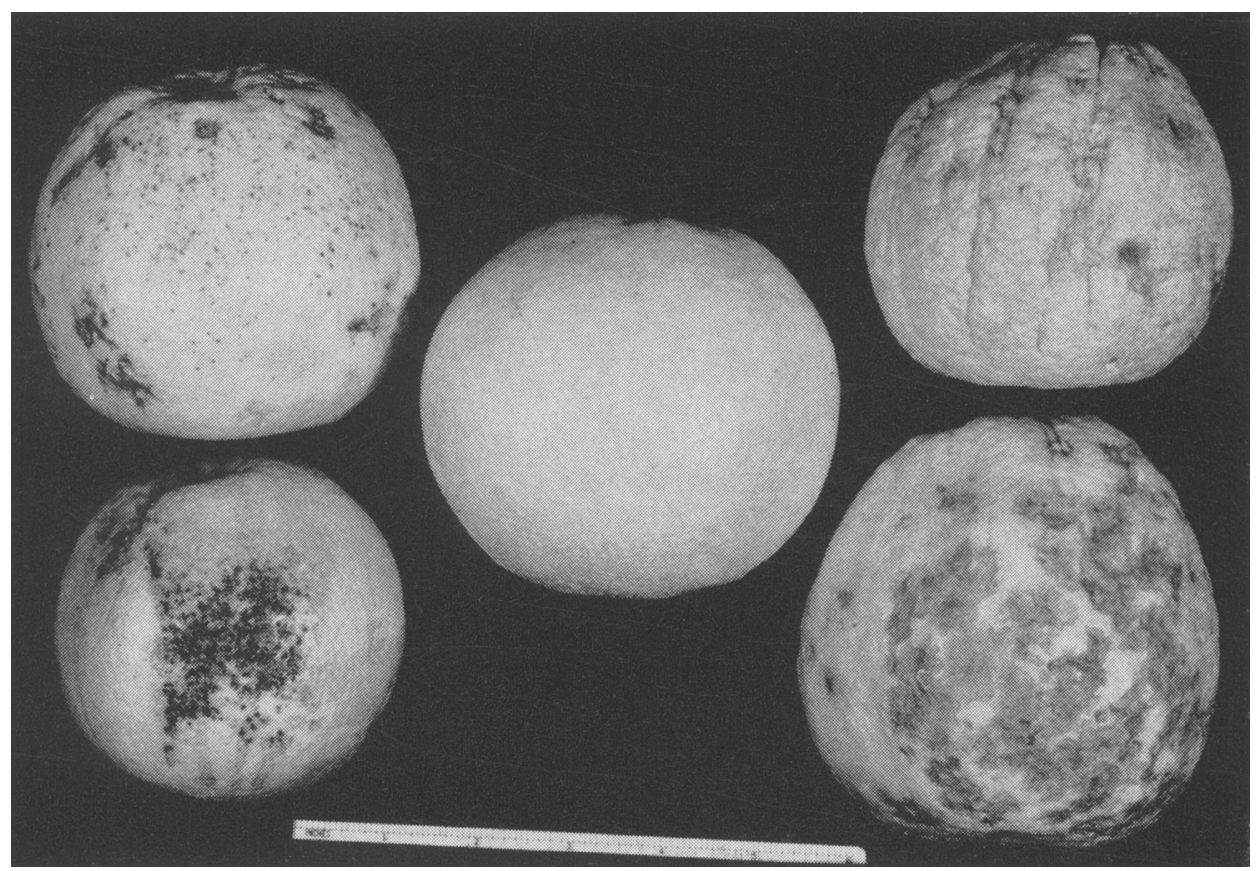

Fig. 2. Center grapefruit is healthy; others show typical copper-deficiency symptoms. 


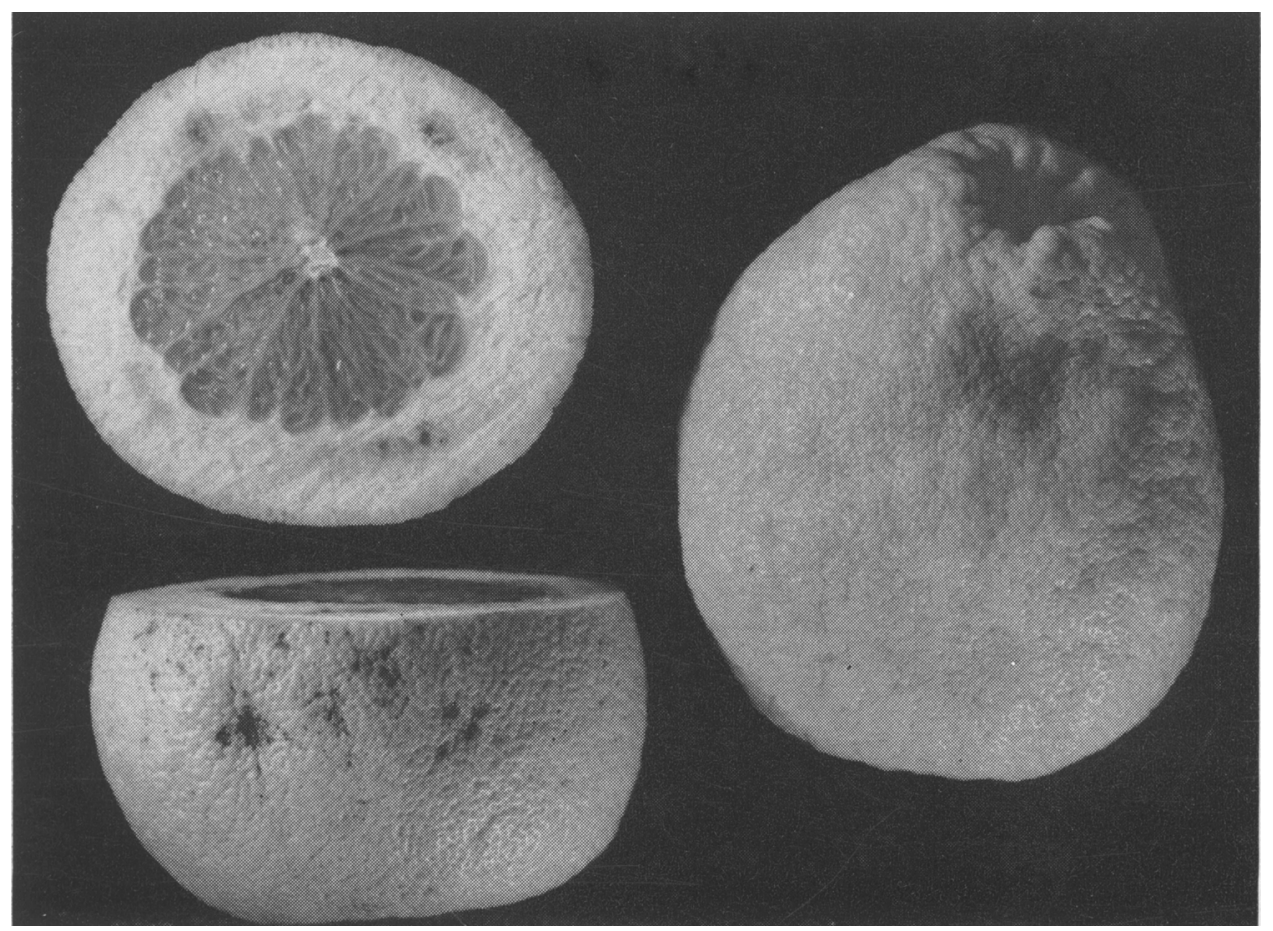

Fig. 3. Grapefruit showing interior symptoms of severe copper deficiency.

Symptoms identical to those described above were observed in the spring of 1962 in orchards B and D. No symptoms typical of copper deficiency other than poor appearance and lack of vigor were observed on the Valencia orchard C adjacent to the grapefruit orchard B. It should be emphasized that both grapefruit orchard B and Valencia orange orchard $\mathrm{C}$ were on rough lemon rootstock and both received similar cultural and management practices. This suggests that grapefruit trees are more sensitive than orange trees to a low copper supply.

When orchard A was initially examined, the coarse appearance of the fruit and the absence of gumming on twigs suggested the possibility of boron deficiency. This possibility was tested by the application of borax in randomized block experimental design consisting of four single trees replicates at two separate locations in the orchard. Treatments were: boron ( 80 grams of borax broadcast around drip of tree), boron plus copper spray, and copper spray only. The copper spray contained 2 pounds of copper sulfate, plus 2 pounds of: hydrated lime per 100 gallons of water. The copper spray treatment was applied to the remainder of the orchard soon after the borax treatments were applied, and annually in the spring thereafter.

A leaf sample representative of orchard A was taken from fruiting terminals during the period of initial inspection and before any treatments were applied in March, 1958. Although this first sampling represented mature leaves approximately 1-year old, the extremely low level of copper (less than $0.75 \mathrm{ppm}$ ) would not have been expected to have resulted from a seasonal variation unless copper was deficient. The concentrations of other trace elements and the major elements were normal when compared to Chapman's (1949) standards.

Leaves of the treated trees showed pronounced boron-toxicity symptoms within 3 months from the time of borax application. Concentration of copper in 


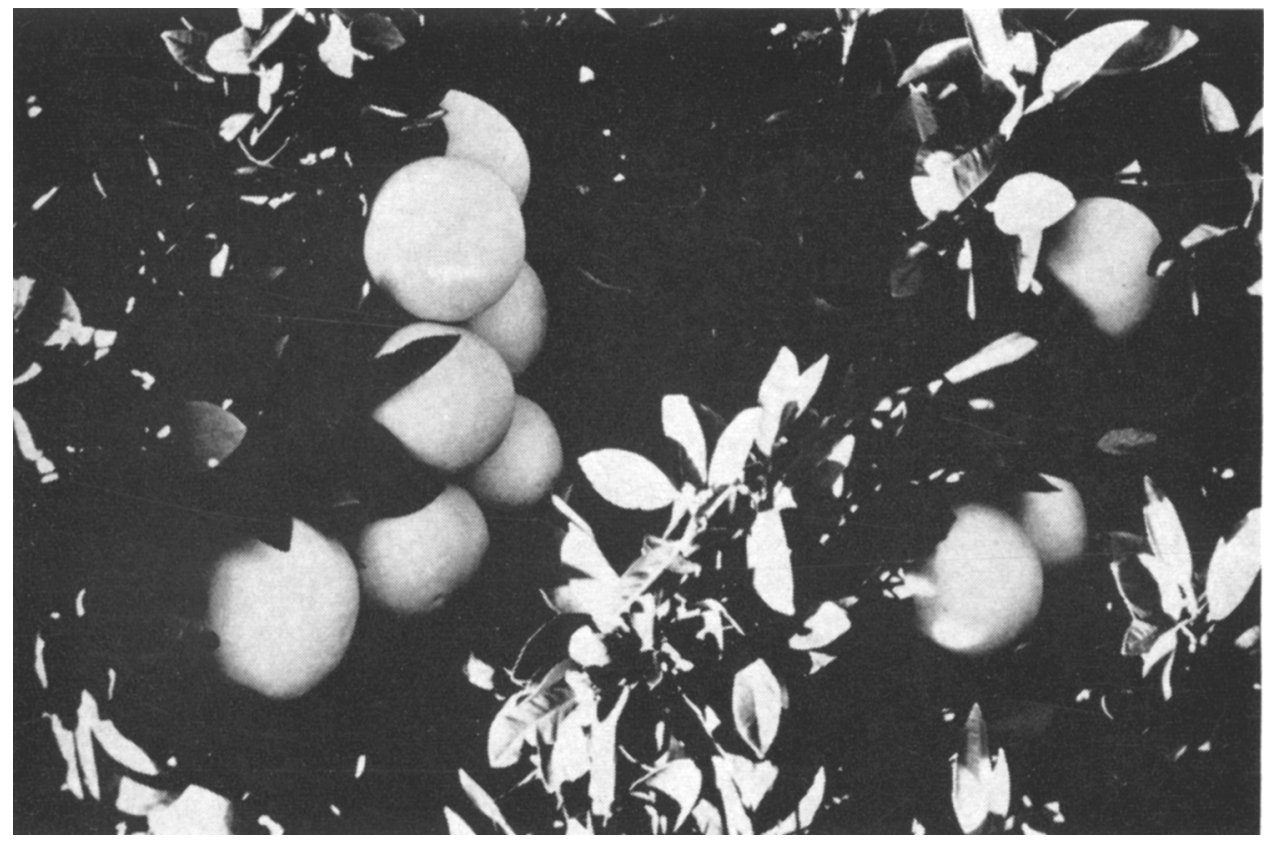

Fig. 4. Grapefruit in orchard where copper deficiency has been corrected.

the leaves from the borax treatment reniained in the deficient range $(1.3 \mathrm{ppm})$, while the copper content of the leaves from trees treated with copper spray increased to $25 \mathrm{ppm}$. Symptoms of copper deficiency were corrected the first year, and there was no recurrence of the problem on the sprayed trees. The unsprayed trees, including the boron-treated trees, continued to show symptoms of copper deficiency, thus eliminating boron deficiency as a cause of the generally poor appearance of the orchard.

Leaf samples were collected in 1962 from orchards B, C, and D. Grapefruit leaves from orchards $\mathrm{B}$ and $\mathrm{D}$ contained 0.75 and $1.5 \mathrm{ppm}$ copper, respectively, and the orange leaves less than $2.0 \mathrm{ppm}$ copper. Since only the grapefruit trees showed severe symptoms of copper deficiency, it is possible that grapefruit trees are more sensitive than orange trees to a low copper supply. The most accurate method of copper deficiency diagnosis is leaf analysis. A consistently low copper content of leaf samples from orchards A, B, C, and D suggested a low copper content in the Hanford sandy loam soil of this district. Accordingly, virgin soil samples were collected from the district and their copper contents were found to be $1.6,3.2,6.6,6.6$, and $10.0 \mathrm{ppm}$; these values were the lowest found in a number of southern California soils. New Zealand soils with a total copper content less than $10 \mathrm{ppm}$ are classified as copper deficient by Taylor et al. (1956). Purvis and Ragg (1962) analyzed 100 soils from a copper deficient area in south-east Scotland and concluded that soils with less than 2 ppm total copper are likely to be deficient for oats. Bould et al. (1953) working with fruit trees found copper deficiency where the fraction of total soil copper soluble in $0.1 \mathrm{NHC} 1$ was in the 0.9 to $1.6 \mathrm{ppm}$ range. Mitchell (1955) reported that copper in soils was usually in the 3 to $100 \mathrm{ppm}$ range. These observations support the conclusion that the severe copper deficiency observed in grapefruit orchards A, B, and D was due to a low total copper content of the soil. 


\section{SUMMARY}

Symptoms of severe copper deficiency were visually diagnosed in three grapefruit orchards near Hemet, California. Typical symptoms of copper deficiency were dieback of young twigs, chlorosis of terminal leaves, and misshapen, rough fruit with brown necrotic spots on the outside and gum pockets in the albedo. Gumming on twigs, a typical symptom of copper deficiency reported from other areas, was not identified.

A possibility of boron deficiency was tested by a randomized block experimental design consisting of four single tree replicates at two separate locations in the orchard. Treatments consisted of 80 grams of borax per tree, borax plus copper spray, and copper spray only. Visual symptoms of copper deficiency were corrected by a copper spray. Copper content of grapefruit leaf samples was generally less than $0.75 \mathrm{ppm}$ and total copper content of virgin soil from the area as low as $1.6 \mathrm{ppm}$. These observations and data emphasize that visual symptoms are initially helpful in diagnosing copper deficiency of citrus in southern California, but a final positive diagnosis depends upon copper analysis of leaf material and soils.

\section{LITERATURE CITED}

Bould, C., D. J. D. Nicholes, J. A. H. Tolihurst, and J. M. S. Potter

1953. Copper deficiency of fruit trees in Great Britain. Jour. Hort. Sci. 28:268-77.

CAmp, A. F., H. D. Chapman, and E. R. ParkeR

1949. Symptoms of citrus malnutrition, Chapter IX, pp. 307-65 in Hunger Signs in Crops, G. Hambidge (editor) a symposium. Amer. Soc. Agron. and National Fert. Assoc., Washington, D.C.

Chapman, H. D.

1949. Citrus leaf analysis. Calif. Agr. 3(11):10, 12, 14.

Mitchell, R. L.

1955. Trace elements, Chapter 9, pp. 253-85 in Chemistry of the soil, edited by Firman E. Bear. Amer. Chem. Soc. Monograph No. 126, Reinhold Publishing Corp., 430 Park Ave., N.Y.

Pratt, P. F., and G. R. BRADFord

1958. Separation and determination of total copper and zine in soils. Soil Sci. Soc. of Amer. Proc. Vol. 22 (5) :399-402.

Purvis, D., and J. M. RAGG

1962. Copper-deficient soils in south-east Scotland. The Jour. of Soil Sci. 13(2):241-46.

Taylor, N. H., I. J. Cunningham, and E. B. Davies

1956. Soil type in relation to mineral deficiencies. Paper No. 32, presented before the 7 th International Grassland Congress, Palmerston North, New Zealand.

VAnselow, A. P., and G. F. Liebig, JR.

1948. Spectrochemical methods for the determination of minor elements in plants, waters, chemicals, and culture media. (mimeo.) Calif. Agr. Exp. Sta., Berkeley, California.

WALlihan, E. F.

1953. Iron chlorosis, what is it Citrus Leaves $33(1): 12-13$. 

The journal HILGARDIA is published at irregular intervals, in volumes of about 650 to 700 pages. The number of issues per volume varies.

Single copies of any issue may be obtained free, as long as the supply lasts; please request by volume and issue number from:

$$
\begin{aligned}
& \text { Agricultural Publications } \\
& \text { University Hall } \\
& \text { University of California } \\
& \text { Berkeley 4, California }
\end{aligned}
$$

The limit to nonresidents of California is 10 separate titles. The limit to California residents is $\mathbf{2 0}$ separate titles.

The journal will be sent regularly to libraries, schools, or institutions in one of the following ways:

1. In exchange for similar published material on research.

2. As a gift to qualified repository libraries only.

3. On a subscription basis $-\$ 7.50$ a year paid in advance. All subscriptions will be started with the first number issued during a calendar year. Subseribers starting during any given year will be sent back numbers to the first of that year and will be billed for the ensuing year the following Jamuary. Make checks or money orders payable to The Regents of The University of California; send payment with order to Agricultural Publications at above address. 